\title{
Louder Than Words: A Review of Art Space Germany Exhibition 2017
}

\author{
Kamalika Basu \\ University of Calcutta \\ Orcid: oooo-ooo1-7867-568X. Email: kamalika.91@gmail.com
}

\begin{abstract}
A scholarly review of Art Space Germany exhibition organised by Institut für Auslandsbeziehungen, held at National Library, in February 2017, which is to be presented again in Mumbai in September 2017. This article presents a brief description of the artefacts, comments on the stylistic and technical aspects involved, contextualizes the artworks by providing relevant background information of the artists/genres, and offers insight into the overarching theme and message of the exhibition, which especially pertains to immediate socio-political concerns.
\end{abstract}

Keywords: art exhibition, Art Space Germany, identity, integration, 'refugee crisis'.

In a world where words are conveniently politicized in order to represent dominant ideologies of jingoism and social exclusion of the other, the exhibition entitled Art Space Germany: Revisited brings together a wide range of artefacts that challenge normative interpretations of objects and images, and celebrates the integration of distinctive individual and cultural identities through art. Held at the National Library, Kolkata, from February 4 to March 5, 2017, this exhibition organised by Institut für Auslandsbeziehungen (IfA) is scheduled to be presented again in Mumbai, at the gallery of Max Mueller Bhawan from September 9 to October 7, 2017. According to the Director of Goethe Institut, Calcutta, the artists whose artefacts comprise this exhibition exemplify the "German policy under which artists not born in Germany, thrive, work and teach there" (Basu, 2017). The sketches, paintings, sculptures, collages, and mixed media installations created by the featured artists display a remarkable exploration of colour and texture.

Through their artefacts, the two artists, Armando and herman de vries, boldly demonstrate the Dutch tradition of presenting unique artistic philosophies that is marked by the celebrated Dutch painter Vincent van Gogh. The two large paintings by Armando selected for this exhibition, Woody (1984) and Flag (1985), resemble landscapes in black and white, simultaneously hinting at concealed alternate images within. The rough and uneven colouring suggests the expression of emotional turmoil, which seems to be further augmented by the use of the 'impasto' technique. This also renders to the paintings the impression of having the potential to become a three-dimensional entity.

The name Armando, one that the artist is now known by, is Latin for the phrase "by arming oneself" (Muller, 2013, p. 25). Born in 1929, he was witness to the German Occupation of

(C) AesthetixMS 2016. This Open Access article is published under a Creative Commons Attribution Non-Commercial 4.0 International License (http://creativecommons.org/licenses/by-nc/4.0/), which permits non-commercial re-use, distribution, and reproduction in any medium, provided the original work is properly cited. For citation use the DOI. For commercial re-use, please contact editor@rupkatha.com. 
the Netherlands and had grown up near a transit camp. Ursula Zeller, the curator of the exhibition, explains the work Flag as the reflection of his family's sufferings under the Nazi regime (Basu, 2017). Armando himself explains his relationship with the two colours, black and white, in his book From Berlin where he writes -

"The past? The past is a patch of darkness. It's black with a zillion shades of grey. The future is white. Feel free to scribble on it to your heart's content" (Armando, 1996, p. 20).

Whereas the association of black with violence and white with hope is not surprising, the juxtaposition of the two colours to represent a natural setting is rather extraordinary as a concept. For Armando, nature is an accomplice of the violence that occurs therein and he thereby judges it to be guilty as it "grows undisturbed and erases all traces" (Muller, 2013, p. 25) of the perpetrated crime. While the titles of the two exhibits do not betray this association, his other large paintings in black and white have titles which translate to "Observation of the Enemy", "Battlefield", "Guilty Landscape", "Prussian", and "Head". Since 1979, he has moved to Berlin, "the city of the enemy" (Muller, 2013, p. 25), where he has been working. This seems concurrent with his artistic fascination with places which act as the centre of an event and subsequently underlines the unique relationship between experience and art.

While Armando acquired for himself a new name that marks him as an artist, herman de vries uses small fonts to write his name in order "to avoid hierarchy" (Wright, 2015). The two artworks on display at the exhibition are titled "Terre Provençale" (1991) and "Two Days under the Hawthorn Hedge" (1992). Both the artworks display a pleasantly vivid variety of earth tone where, considering exclusively the aspects of form and colour, the former is structured in a grid-like pattern whereas the components of the latter seem scattered over the expanse of the frame. The art of this artist demands very little speculation. Simply as the titles indicate, the first artwork consists of mud rubbings on paper sheets from samples of different shades of earth of Provence. The marks of the artist's fingers, visible over the gently rubbed base layer, add to organic quality of the artwork. The latter is a collage which the artist has created by placing a sheet of paper underneath a bush for two day and then pasting the leaves as they had fallen upon it (Basu, 2017). These artworks thus make it evident that the philosophy of such art is far removed from the idea of presenting a contrived entity whose meaning must be deciphered by convoluted thought processes. On the contrary, these seem to represent the simple beauty of nature which must be realised by complete absorption of all mental faculties of the viewer.

de vries, now an 86 year old artist, has had a background in naturalism as he had attended a gardening school, been involved in agricultural work in France, and then pursued research on plant diseases and Applied Biology in his formative years (Timeline section, n.d.). He now lives with his wife in the Black Forest of Germany. Along with conducting research on psychedelic plants, he keeps what is referred to as his 'earth bank' which contains more than 8000 specimens of earth from different locations of the world. He is known to keep them unmixed in order for them to retain their original quality (Wright, 2015). Each specimen of earth thus captures the story of the place in its essence, including the lives of people living on it and the plants growing there. In the academic paper titled "Rendering Aesthetic Impressions of Text in Color Space", the authors observe -

"Terre Provençale evokes more broadly than for a single person, potentially evoking specific meaning for a whole community of people, namely, the residents of Provence, and to a lesser degree, all of mankind, who share a common experience with the various shades of yellow, brown, and red earth" (Liu \& Maes, 2005, p. 2). 
The latter artwork is thus seen to reinforce the recurrent theme of recognition and acceptance of the inherent plurality of identity, while the former represents an aesthetic unification through the integration of seemingly disparate components.

Per Kirkeby's untitled abstract paintings which seem to depict images of the natural world also display a penchant for capturing the shades that permeate the earth. The visible etchings and brush strokes render to the works a texture that resembles the coarseness of organic material which pervades all natural entities, regardless of their particular forms.

Candice Breitz's exhibit, Factum Kang (2009), appears as a dual-channel video installation with two vertically-mounted plasma displays placed adjacent to one another. A sitting bench with headphones attached to this system is placed in front of it. Two videos of apparently the same person appear on the screens in an endless loop, with one of the screens going blank at times. The only point of distinction to the observer's eye would be the difference between the partings of hair of the interviewees. Once the audience takes her seat and puts on the headphones, she can watch an interview edited across the two screens and realise through the respective speeches that the interviewees are indeed identical twins. Depending on the specific point of time when the audience begins to participate in this piece of installation art, she becomes privy to a part of their stories. On listening at length, it is revealed that despite their apparent likeness in physical features, similar body language, identical make up, costume and setting of the shoot, and years of shared childhood, the twins portray very distinctive, sometimes contradictory, personalities by presenting different perceptions of their lives and of the world at large. The interviews seem to be edited to synchronize at points and sharply break away at others. As one undergoes the audio-visual experience as a third person and understands the differences underlying the similitude, by following the sudden cuts in the editing process, one also detects a gap in communication that exists between the two siblings. Again, despite the disparate trajectories that the twins have undertaken, the fact remains that they share a profound connection that is rooted to the very core of their unified existence.

Breitz is a South African artist, presently working in Berlin as a professor, who works primarily in the domain of video and photography. The artefact selected for this exhibition, Factum Kang (2009), is an artistic work created out of the interviews of the monozygotic twins Hanna and Hanjoo Laurie Kang, who were filmed on separate days for five to seven hours each, in the absence of the other sibling, while being interviewed on the same set of questions (Breitz, 2010). Factum (2010) is a collection of the edited interviews of eight sets of twins, including one of triplets, whose title is inspired from Robert Rauschenberg's almost identical paintings named Factum I and Factum II (1957). The direction and editing style of Breitz plays with the ideas of fact and fiction, and the generalised association between the two. The artist implements this idea of impressions created by fiction and reality with regard to human identity most interestingly in her recent work Love Story (2016), which is a seven-channel installation that "interrogates the mechanics of identification and the conditions under which empathy is produced" (Breitz, 2016). She works closely on lengthy interviews of six individuals who have fled from their native countries due to some oppressive conditions, and recreates the same narratives with the help of famous actors in order to highlight the tendency of the audience to render more importance to the fictitious enactment by personalities they recognise distinctly rather than the true accounts of these individuals they 'otherise' as refugees. Her works therefore throw light on the usual human propensity for typecasting people based on apparent similarities and differences rather than recognizing the nuanced elements that defines their distinguished identities. Such art seems to 
appeal to the citizens of the global community to look deeper and to acknowledge people as individuals rather than reducing them as an insignificant part of a nebulous whole.

The artefact titled Flotsam (1997) is a sculpture created by the British artist Tony Cragg out of laminated plastic. A series of what seem to be some of his sketches, incidentally titled Sculpture (1997), that are based on shapes and forms melting into one another, is also on display. The abstract shape of the sculpture, along with his sketches that are on display, exemplify his keen interest in the form of objects. The allusion to the 'refugee crisis' is repeated once again in the title of the artefact, which refers to "people who have no homes or work and who wander about in a helpless way" (flotsam, 1997) as much as "an untidy collection of unimportant or useless objects" (flotsam, 1997). While the second definition holds literally true because Cragg is known to use material that are disposed of by others, the metaphorical reference to idea of people adrift in the sea under desperate conditions having consequential potential seems equally obvious. Regarding the material of his craft, he says to Emma Crichton-Miller, "These are not at all things that people need for any practical purpose in the world ... But they do reveal so much for me as I am making them. They offer me a new way to see the world, and that is all I am interested in" (Crichton-Miller, 2011). Most of his other works are also a result of organisation of discarded material, but the activity that he seems to delight in is the creation of "the things that aren't there. There is no point in copying what is there - the role of art is to open a door onto other realities" (Crichton-Miller, 2011). This is reminiscent of Oscar Wilde's wish for an artistic world in The Decay of Lying where "over our heads will float the Blue Bird singing of beautiful and impossible things, of things that are lovely and that never happen, of things that are not and that should be" (Wilde, 1902, p. 76). Cragg's Flotsam appears to be such an artefact that attempts to map the invisible, imperceptible space through matter and to capture possibilities through form. Abstraction, for this artist, is therefore not merely a stylistic approach but a necessary step that engenders imagination.

A similar experimentation on space with matter may be detected in Giuseppe Spagnulo's artefact Cerchio Spezzato (1972) which is cast in iron. As the name suggests, the piece represents a broken circle, but remarkably one that has more than two dimensions. Installed at one corner of the room, the artefact attracts attention by dint of its sheer volume and bold display of strength. The abstraction of this artwork appeals to the spectator to seek more information about the artist and his art who had worked actively in steel mills, blast furnaces and workshops, where he created art alongside the workers. The paintings exhibited in the gallery created out of thick layers of coal in order to resemble barrels and lids used by labourers are significant in highlighting the heaviness associated with such labour. The fact that he joined in the protests of 1968 is evident from most of his works as their enormous dimensions themselves underline the dangers and the vigorous labour involved in the process of industrial production. Like Tony Cragg's work, the art of Spagnulo seems to play with the idea of space. He is noted to remark on his interest in experimenting with "the quantity of space that a form manages to set into movement" (About Giuseppe Spagnulo, n.d.). Despite being grounded in reality, the genre of his work marks a tendency towards conceptualism. In keeping with the rest of the works in the exhibition, his creations seem to highlight the fact that art renders significance to ideas and objects which usually go unnoticed.

The genre of conceptual art is further exemplified in the installation of Joseph Kosuth which presents an enormous photograph framed in wood and its 'reproduction' in the German language. The content of the text seems to be expressed in the corresponding photograph and vice versa. Without any verbal explanation, it becomes clear that the artist is presenting the same 
idea through different media. This idea itself is the art, as Kosuth would claim. One of the pioneers of conceptualism, Joseph Kosuth refutes the idea of equating art with the material object that represents it (Osborne, 2002, p. 232). The medium or technique is therefore rendered redundant when compared to the essence that is conveyed by any means chosen for it. In fact, one of his noted works titled One of Three Chairs (1965), which comprises a chair, its photograph taken at the site of the particular exhibition, and its dictionary definition presented in words, demonstrates that a concept remains constant even though the relative elements like the place and time of its display are altered. This presents a unique point with respect to the other exhibits as it attempts to find a pulse that runs deeper than the apparent differences and underlies all of existence.

A set of three photographs, Marianne Eigenheer's artwork named Your time, my world (1998) captures in images monochromatic portraits of people, postcards, toys, and paintings on a wall. While the yellowish tinge to the photographs displayed at the exhibition imbue them with the notion of passage of time, the presence of images of photographs within photographs denote the multiple levels associated with thought and memory. The objects in the photographs appear to be material manifestations of a lost past. The idea of being framed as a photograph itself reinforces the idea of nostalgia and the common human desire to hold on to memories of a time that cannot be retrieved.

The title of the artwork indicates the intersection of time and space, where the two phenomena may pertain to two different people such that the remnants of one's time in the form of memorabilia continue to occupy the space of another's world. Again, the words 'your' and 'my' may refer to the audience and the artist respectively. The private world of the artist encapsulates and evokes sentiments with which the audience may relate a specific time of their lives, despite the fact that the artist and the audience hardly know much about one another. This establishes an unspoken bond between human beings which is more fundamental than the mere difference in appearances. Much like Kosuth's artefacts, Eigenheer's works subtly imply the existence of certain inexplicable intrinsic yearnings which reveal the capability of human beings to relate with each other. The Swiss artist, Marianne Eigenheer has been a student of music, art history, and psychology. Her works, which include painting and photography, usually trace the notion of thoughts and instincts which are indispensable to the human psyche.

The three photographs by Marie-Jo Lafontaine are representative of her fascination with the element of fire, which is epitomised in her installation titled We Have Art so that We Do Not Perish by Truth (1991) where she "contrived to render the Glyptothek in Munich transparent by pasting photographs of flames into the recesses of the dome thus creating the illusion of looking through apertures in a building that is being consumed by fire" (Elwes, 2015, p. 13). The combination of colours in each of her three exhibits - Every Angel is Terrible (1991/92), Homme cagoulé portant le feu (1986), and Bateau de feu (1996) - accentuates the image of flames. Although her art is based on specific social issues, "she looks for the general in the particular, and delves into the basics of human existence" (Grosenick \& Becker, 2001, p. 294). For instance, the artefact Every Angel is Terrible is based on the war in the former Yugoslavia and the riots in Los Angeles, but the image of flames represents the state of chaos that is rampant in the entire planet (Castant, 2011).

Internet Resident (1997), a complex machine resembling a robot created out of surveillance cameras, Polaroid camera, and laser disc player. In this piece, the artist orchestrates disparate objects which act as complicit components of the machine. The other exhibit, entitled Candle TV (1975), may indicate observation to be the source of light and knowledge. In the tradition of the 
Fluxus movement, Nam June Paik's artwork presents something unforeseen and radical, disturbing the status quo, which opens up new avenues both for production and interpretation of art.

A series of ten photographs called Atlantic Wall (1995) appears in monochrome, in each of which a fragment of the fortification seems to be melting into the landscape, being reclaimed by nature. This sequence is preceded by an expansive map that traces the complete length of the extensive belt of defensive structures built by Nazi Germany along the coast of continental Europe and Scandinavia in anticipation of an allied invasion of Nazi-occupied Europe from the United Kingdom. An excerpt from Paul Virilio's Bunker Archaeology (1994) is also provided, possibly in order to provide context to the exhibit. Each photograph in this series by Magdalena Jetelová has a caption projected upon the relics such that the meanings of the words seem to pervade the objects themselves. The positioning of the font of the words corresponds with that of the images. According to Ursula Zeller, the "long exposures and twilight cast a misty veil" (Basu, 2017) upon the photographs. To the observer, it seems that although the fragments are a concretized reminder of atrocities perpetrated by the Nazi regime not only against mankind but against the universe as a whole, the images of the ruins being devoured by the elements of nature seem to reinforce the idea that no wall can withstand the force of time. Such a strong message, with reference to one of the most abhorrent events in the history of human civilisation, serves as reassurance in times of rising threats of segregation and xenophobia.

The image of the wall returns in an entirely new connotation with Christine Hill's People's Boutique Official Template (1999), which demonstrates a form of interactive art. If one visits the gallery a few days into the exhibition, one may expect to find a wall on which some sheets, designed to a particular template, have been put up, along with the photographs of strangers and a few words about them. A Polaroid camera, a number of unfilled sheets and pens may be found on a desk nearby. The spectator will eventually realise that this wall is constructed out of the profiles of the visitors to the exhibition and with their thoughts, histories, and identities etched on it through photographs and scribbled words. The spectators are therefore encouraged to participate in the creation of the artwork and, in the process, become artists themselves. The beauty of this artefact lies in its process of 'becoming', and its accommodation of multifarious personalities who come together for the sake of art to construct a wall which integrates instead of creating divides.

The final artefact Here and There (1989), created by the Turkish artist Ayşe Erkmen, is placed at the farthest end of the exhibition gallery that is elevated above the rest by a small flight of stairs. It consists of sixteen trapezoid metal bodies that are actually parts of differently coloured old cars (Basu, 2017). They lie scattered here and there, just as the title of the artwork suggests. However, it is interesting to know that despite the apparent disharmony among the different pieces, the spectator may rest assured that when arranged properly, the disjointed parts form a remarkably organised piece of art in the form of a multicoloured arch. The image of the artefact thus arranged can be seen on the photograph on the exhibition catalogue.

Although the exhibition builds upon the premise of the biographical journey of the artists who have chosen Germany as the locus of their creative pursuits, a strong undercurrent of a sociopolitical message is manifest in all of the artefacts on display. The background of each artefact is inherently related to the minds which have nurtured them, thus leading to such a rich variety of creative expressions. The history of the conception of the artworks, coloured by the disparate places of their origin, reinforces the fact that the success of the German tradition of art (Art Space Germany, n.d.) is a result of not ignoring individual identities but of celebrating them. It is 
important to note that, even if one discounts the intentions of the individual artists which we have explored, the organisation of this exhibition at this juncture in history of mankind is a momentous occasion. In the context of a progressively fracturing world, where interpersonal relationships and personal opinions of the common man have begun to be tainted by the increasingly normalised politics of hate, fear and xenophobia, the bold statement of this exhibition, advocating the necessity of plurality in contemporary society, is a welcome counterdiscourse. The idea of recognition and acceptance of distinct individual identities without prejudice passes effortlessly from the realm of art to society in general. This becomes plainly evident in the unspoken dialogue among the various artefacts in this exhibition, each with a unique perspective and yet sharing a common message - an appeal for assimilation without homogenisation. Thus, the perspicacious spectator may expect to experience the silence of the exhibition hall speaking louder than words.

\section{References}

About Giuseppe Spagnulo. (n.d.). Artsy. Retrieved from https://www.artsy.net/artwork/giuseppe-spagnulocubo

Armando. (1996). From Berlin, 20.

Art Space Germany. (n.d.). Retrieved from http://www.ifa.de/en/visual-arts/exhibitions-abroad/finearts/art-space-germany.html

Basu, A. (2017, February 4). Art that transcends borders. The Telegraph. Retrieved from https://www.telegraphindia.com/1170204/jsp/calcutta/story_133964.jsp

Breitz, C. (2010, July 21). Factum Kang. Retrieved from https://vimeo.com/13514467

Breitz, C. (2016). Love Story. Retrieved from http://www.candicebreitz.net/

Castant, A. (2011). Marie-Jo Lafontaine: Dans le cabinet du bâtonnier de Bruxelles. Alexandre Castant: essayiste et critique d'art. Retrieved from http://www.alexandrecastant.com/texte.php?texte_id=82

Crichton-Miller. (2011, July 29). Edinburgh Festival 2011: Tony Cragg interview. The Telegraph. Retrived from http://www.telegraph.co.uk/culture/theatre/edinburgh-festival/8668954/Edinburgh-Festival-2011Tony-Cragg-interview.html

Elwes, C. (2015). Installation and the Moving Image, 13.

Flotsam. (1997). In Oxford Advanced Learner's Dictionary.

Grosenick, U., \& Becker, I. (2001). Women Artists in the 2oth and 21st Century, 294.

Liu, H., \& Maes, P. (2005). Rendering Aesthetic Impressions of Text in Color Space. International Journal on Artificial Intelligence Tools, 2. Retrieved from http://www.hermandevries.org/articles/archives/article_2005_liu-maes.pdf

Muller, S. D. (2013). Dutch Art: An Encyclopedia, 25.

Osborne, P. (2002). Conceptual Art: Themes and Movements, 232.

Timeline section. (n.d.). herman de vries. Retrieved from http://www.hermandevries.org/timeline.php

Wilde, O. (1902). The Decay of Lying, 76. 
Wright, K. (2015, May 21). herman de vries: 'Other artists work with mechanical things. I work with nature. Independent. Retrieved from http://www.independent.co.uk/arts-entertainment/art/features/hermande-vries-other-artists-work-with-mechanical-things-i-work-with-nature-10267144.html

Kamalika Basu is a recent MPhil graduate in English from University of Calcutta. She has completed her post-graduation degree from the same university in 2014, after having graduated from Presidency College in 2012. She research interests include modernism, postmodernism, and Foucauldian discourse analysis. She has authored a thesis entitled "Death of the Artist: A Study in Two Texts". She has also published two articles entitled "In Search of a Selfhood: Metropolitan and Individual Space-Time in Murakami's Novels" in the peer-reviewed journal Netaji Nagar Journal of English Literature and Language, Volume: 4, January 2016 Issue (ISSN No. 2320-4109) and "The Poetics of Wallace Stevens: Reclamation of Reality" in Efflorescence Issue 72016 (ISSN No. 2278-3873). She was a participant in T. S. Eliot International Summer School 2017, organised by IES, University of London. Apart from academics, she also writes opinion pieces and other articles for journals, and is interested in art, music, and social work. 